LAWRENCE LIVERMORE N A TIO N A L LABORATORY

BioWatch in a Box

M. T. McBride, J. M. Dzentis, R. M. Meyer

February 3, 2006 
This document was prepared as an account of work sponsored by an agency of the United States Government. Neither the United States Government nor the University of California nor any of their employees, makes any warranty, express or implied, or assumes any legal liability or responsibility for the accuracy, completeness, or usefulness of any information, apparatus, product, or process disclosed, or represents that its use would not infringe privately owned rights. Reference herein to any specific commercial product, process, or service by trade name, trademark, manufacturer, or otherwise, does not necessarily constitute or imply its endorsement, recommendation, or favoring by the United States Government or the University of California. The views and opinions of authors expressed herein do not necessarily state or reflect those of the United States Government or the University of California, and shall not be used for advertising or product endorsement purposes.

This work was performed under the auspices of the U.S. Department of Energy by University of California, Lawrence Livermore National Laboratory under Contract W-7405-Eng-48. 


\section{BioWatch in a Box}

Mary T. McBride and John M. Dzenitis (Lawrence Livermore National Laboratory), Richard M. Meyer (Centers for Disease Control and Prevention).

BioWatch, the U.S. Department of Homeland Security (DHS) environmental monitoring program, has been successfully operating in many of the nation's urban centers since early 2003. This early warning environmental monitoring system can detect trace amounts of biological materials in the air, and has been used to provide information to assist public health experts determine whether detected materials are due to an intentional release (bioterrorism incident) or due to minute quantities that occur naturally in the environment. BioWatch information enables federal, state, and local officials to more quickly determine appropriate emergency response, medical care and consequence management.

In the current BioWatch system, air is sampled by a network of distributed aerosol collectors, and the resulting filter samples are taken to a central analytical laboratory for processing. Samples are processed using several individual TaqMan ${ }^{\text {TM}}$-based PCR assays designed to test the sample for different biological agents. The established protocol requires that any individual presumptive screen reactive test be re-analyzed using a much more extensive panel of assays. Even though this kind of testing is time-consuming and labor intensive, BioWatch has analyzed well

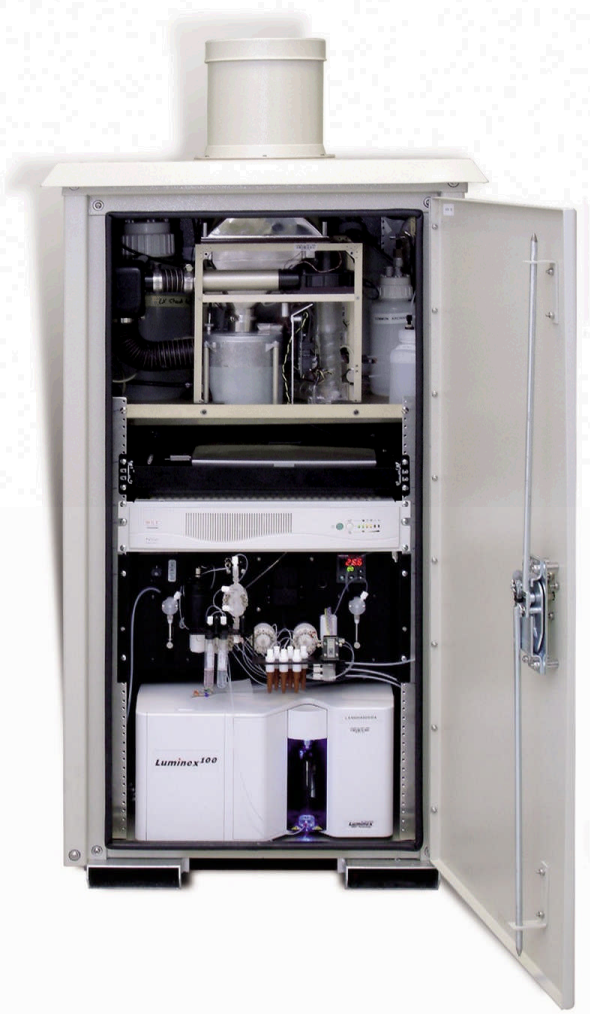

Figure 1. The Autonomous Pathogen Detection System "BioWatch in a Box" over two million samples with zero false positives to date. Although the current system has exhibited unparalleled performance, the time between aerosol collection and analytical results may be long (averaging 24 hours), depending upon collector and lab locations), and because the system is very labor intensive, it is very expensive to operate.

To overcome these shortcomings, Systems Engineering and Design (SED) within the Science and Technology Directorate of DHS is working with Lawrence Livermore National Laboratory (LLNL) and the Center for Disease Control (CDC) to develop and field the Autonomous Pathogen Detection System (APDS), often referred to as "BioWatch in a Box" (Figure 1). Additionally, under DHS funding, LLNL and CDC have co-developed a deeply multiplexed multi-loci panel of nucleic acid assays (27-plex) for detection of 8 different 
biological threat agents. This panel of assays is under final evaluation by the CDC and will be considered a validated panel in the coming months following a multicenter performance study. After validation, the assays will be commercially produced and be available for purchase by all members of the LRN. Because the multiplexed assays are contained within a single tube and are performed simultaneously, the multiplexed panel offers significantly enhanced detection capabilities with a $60 \%$ reduction in costs and significant savings in labor relative to the costs and time required to run each individual assay. The multiplexed assays represent the next-generation of BioWatch assays and will compliment the existing singleplex TaqMan ${ }^{\mathrm{TM}}$-based detection assays currently in use within the BioWatch laboratory network. Additionally, these assays are compatible with high-throughput sample "surge" processing and analysis capacity robotics: sample processing capacity currently stands at about 4,000 samples per 10 hour shift, using a single line of equipment and a staff of two.

Over the coming months, these assays will be transitioned to the APDS. The APDS is a stand-alone instrument capable of continuous, fully autonomous monitoring for multiple airborne biological threat agents. ${ }^{1,2}$ The system was developed to protect people in critical or high-traffic facilities (such as airports, subways, government and commerce centers) and at special events (such as conventions and sporting events). The current version of the APDS continuously collects samples from the air into water, performs multiplexed immunoassays, ${ }^{3}$ analyzes the results, sends silent notification to monitoring authorities, and performs confirmatory $\mathrm{TaqMan}^{\mathrm{TM}} \mathrm{PCR}^{4}$ in response to an immunoassay presumptive screen reactive result, all in continuous unattended operation that has been benchmarked at 7 days. APDS is in operational test and evaluation in New York City. The total number of samples APDS has analyzed in the field stands at 12,816 samples, which is equivalent to a total of 77,788 immunoassays and 834 PCR assays.

Although the current APDS does not conduct multiplexed nucleic acid assays, the system contains all of the functions (aerosol collection, PCR, reagent manipulation, flowcytometry) required to execute the multiplexed PCR assays. Enabling the units to run the full multiplexed LRN PCR panel in the field is clearly feasible without extensive hardware or software development. With support from SED, LLNL will perform proofof-concept experiments that demonstrate APDS could automate the multiplexed nucleic acid assay process and will then fully automate and test the process on the bench and in an APDS in the laboratory. Concurrently, the CDC will operate a Multiplex PCR APDS platform to verify the performance of the automated fluidics system compared to the high-throughput laboratory process. The performance of six APDS instruments in the field in NYC will be evaluated in the phase of operational test and evaluation. Upon completion of this work, the APDS systems will then be capable of running the full LRN panel for long periods of time in a fully automated mode, where air is continuously sampled and tested using a full panel of screening and confirmatory assays in a single test. This will result in significant labor reduction which translates into cost-savings. There will be more than a ten-fold improvement in time resolution for sampling and in time from sample start to assay result. 
UCRL-TR-218632

\section{References}

1. Hindson, BJ; Makarewicz, AJ; Setlur, US, et al. "APDS: the autonomous pathogen detection system", Biosens. Bioelectron., 20, 1925-1931, (2005). UCRL-JRNL204194

2. McBride, M.T.; Masquelier, D.A.; Hindson, B.J.; Makarewicz, A.J.; Brown, S.B.; Burris, K.; Metz, T.; Langlois, R.G.;Tsang, K-T.; Bryan, R.; Anderson, D.O.; Venkateswaran, K.S.; Milanovich, F.P.; Colston, B.W. "Autonomous Detection of Aerosolized Bacillus anthracis and Yersinia pestis". Anal. Chem, 2003, 75, 5293529. See also Cover Art. UCRL-JC-152946

3. McBride, M.T.; Gammon, S.; Pitesky, M.; O’Brien, T.W.; Smith, T.; Aldrich, J.; Langlois, R.; Venkateswaran, K.S. Multiplexed Liquid Arrays for Simultaneous Detection of Simulants of Biological-Warfare Agents. Anal. Chem, 2003, 75, 19241930. UCRL-JC-151005

4. Hindson, B.J.; McBride. M.T.; Makarewicz, A.J.; Henderer, B.D.; Setlur, U.S.; Smith, S.M.; Guitierrez, D.M.; Metz, T.R.; Nasarabadi, S.L.; Venkateswaran, K.S.; Farrow, S.W.; Colston, B.W.; Dzenitis, J.M. "Autonomous detection of aerosolized agents by multiplexed immunoassays with PCR confirmation". Anal. Chem, 2005, 77, 284-289. 